\title{
Aspectos do Design abordados em Empreendimentos Sociais e Solidários: uma revisão sistemática
}

\section{Aspects of Design addressed in Social and Solidarity Enterprises: a systematic review}

Renata Mayumi Lopes Fujita, Universidade de São Paulo mayumilf@usp.br

Lara Leite Barbosa, Universidade de São Paulo

barbosall@usp.br

\begin{abstract}
Resumo
Este artigo busca identificar o que está sendo abordado atualmente sobre o tema de economia solidária no âmbito do design. Desta forma, aplicou-se a metodologia de revisão sistemática de literatura, com o objetivo de analisar as principais publicações que transpassam esta temática, identificando as características destes estudos e os focos de conteúdos abordados, permitindo a compreensão do estado da arte de pesquisas sobre a economia solidária na perspectiva do design. A pesquisa, realizada no Portal de Periódicos da Capes, resultou em oito artigos, nacionais e internacionais. A análise demonstrou que o termo "empresa social" é amplamente aplicado para descrever formas organizacionais que atuam com o objetivo primordial de desenvolvimento social em um processo de inovação social. A abrangência de tal definição permite considerarmos as experiências da economia solidária em tal contexto. O papel do designer é descrito como um facilitador/mediador em processos para inovação social e sustentabilidade, no entanto, a heterogeneidade das formas organizacionais descritas nos estudos, dificultam a sistematização de um design pensado para a economia solidária.
\end{abstract}

Palavras-chave: Design, Economia Solidária, Empresa Social.

\begin{abstract}
This article seeks to identify what is currently being addressed on the theme of solidarity economy in the scope of design. In this way, the methodology of systematic review of literature was applied, with the objective of analyzing the main publications that transpass this theme, the characteristics of these studies and the focus of contents, allowing an understanding of the state of the art of solidarity economy's research from a design perspective. The research carried out in the Portal de Periódicos da Capes resulted in eight international articles, whose analysis showed that the term "social enterprise" is widely applied to describe organizational forms that act with the primary objective of social development. The scope of such a definition allows us to consider the experiences of solidarity economy in this context. The role of design is described as a facilitator/mediator in the process for social innovation and sustainability, with the reservation that the heterogeneity of the organizational forms described in the studies makes it difficult to systematize a design thought for the solidarity economy.
\end{abstract}

Keywords: Design, Solidarity Economy, Social Enterprise. 


\section{Introdução}

Economia Solidária é um conceito utilizado para descrever modos organizacionais alternativos de produção, comercialização, consumo e finanças, que atuam mediante os valores de solidariedade e cooperação. O termo passou a receber maior atenção no Brasil a partir da década de 1990, quando houve um aumento nas taxas de desemprego devido a crises econômicas. Consequentemente, novos empreendimentos econômicos solidários manifestaram-se como uma alternativa de trabalho e obtenção de renda.

Este movimento que, por meio de uma reorganização dos modos de consumo e produção, visa minimizar as desigualdades da sociedade, pode ser encontrado na literatura internacional com diferentes denominações.

O termo Economia Social advém de um contexto francês, e compartilha com a Economia Solidária as raízes associativistas e a luta dos trabalhadores do continente europeu. Genauto França (2002) destaca que, em um aspecto jurídico, a economia social é utilizada para designar as organizações cooperativas, organizações mutualistas, fundações e associações de grande porte.

O Cooperativismo reúne as experiências das organizações cooperativas, definidas pela Aliança Cooperativa Internacional (ACI) como sendo "empreendimentos controlados e geridos por seus sócios para desempenhar suas necessidades e aspirações econômicas, sociais e culturais em comum". Esta definição delineia a centralidade da autogestão no processo cooperativo, equivalente à concepção do empreendimento econômico solidário, a qual Paul Singer (2002) destaca como sendo a principal diferença entre a economia capitalista e a economia solidária. Rui Namorado (2009) evidência o caráter heterogêneo da experiência cooperativa, com atuação em todo o mundo, abrangendo de pequenos à grandes empreendimentos em diversos setores de atividade.

Ao descrever o contexto histórico do conceito de Empresa Social, Defourny e Nyssens (2010) situam o início da aplicação deste termo na década de 1990, quando o governo italiano organizou as experiências cooperativas do país, sob a legislação de Impresa Sociale. Contudo, os autores afirmam que movimentos similares podem ser identificados em diversos países europeus, com características específicas do contexto social, político e econômico do país em questão. Portanto, é possível associar o conceito de Empresa Social à noção de Economia Social, Economia Solidária ou ao Terceiro Setor.

Compreendemos, mediante a bibliografia analisada acerca dos termos apresentados, que podem existir divergências nos conceitos de Economia Solidária, Economia Social, Cooperativismo e Empresa Social, sobretudo quando são analisadas as experiências de diferentes países, de acordo com seus contextos legislativos, culturais, sociais e econômicos.

Todavia, tais conceitos parecem convergir ao descrever suas experiências como movimentos que atuam em prol de melhoramentos sociais e sustentabilidade, conduzidos de maneira alternativa aos objetivos e valores das empresas capitalistas.

Inserido na discussão acerca do desenvolvimento sustentável da sociedade, estão as conceituações sobre o papel social do design. A Organização Mundial de Design (WDO) situa, em sua atual definição sobre design industrial, o melhoramento da qualidade de vida como um 
objetivo fundamental no processo de resolução de problemas, evidenciando, desta forma, uma responsabilidade socioambiental nas atividades dos designers.

De maneira mais objetiva, Manzini (2008) contextualiza a atuação do design em um cenário transitório, de transformação para uma sociedade sustentável. Em um contexto de design para a sustentabilidade, as competências dos designers correspondem à:

Habilidade de gerar visões de um sistema sociotécnico sustentável; organizá-las num sistema coerente de produtos e serviços regenerativos, as soluções sustentáveis; e comunicar tais visões e sistemas adequadamente para que sejam reconhecidos e avaliados por um público suficientemente amplo, capaz de aplica-las efetivamente (MANZINI, 2008, p.28).

Priorizando a causa social como uma grande motivação da ação do designer, Pazmino (2007) localiza o design social na reunião entre o que é socialmente benéfico e o que é economicamente viável. O objetivo primordial de tal abordagem seria de beneficiar grupos sociais específicos. Além disso, a autora destaca que a prática do design social tende a crescer concomitantemente ao aumento da população de idosos e comunidades empobrecidas, fazendo-se necessária uma visão interdisciplinar por parte dos designers, de forma a atender à estas novas demandas.

Compreendemos, portanto, que existem diferentes abordagens na área do design, que descrevem a atuação do designer em uma conjuntura de desenvolvimento social, ou desenvolvimento sustentável. Qualificamos a economia solidária, como um movimento social que participa da discussão acerca do desenvolvimento sustentável. Sendo assim, questionamos neste estudo: o que está sendo abordado atualmente sobre o tema de economia solidária no âmbito do design? Esta indagação tem como objetivo revisar sistematicamente as principais publicações que transpassam esta temática, identificar as características destes estudos e os focos de conteúdos abordados, permitindo a compreensão do estado da arte de pesquisas sobre a Economia solidária na perspectiva do design.

\section{Metodologia}

Para atender o objetivo proposto neste estudo, aplicou-se a metodologia de revisão bibliográfica sistemática, a qual, segundo Conforto, Amaral e Silva (2011, p.3), é utilizada como um "instrumento para mapear trabalhos publicados no tema de pesquisa específico para que o pesquisador seja capaz de elaborar uma síntese do conhecimento existente sobre o assunto". $\mathrm{O}$ Quadro 1 demonstra sinteticamente, as etapas percorridas para o desenvolvimento deste estudo.

\begin{tabular}{|l|l|}
\hline \multicolumn{1}{|c|}{$\begin{array}{c}\text { ETAPAS DA REVISÃO } \\
\text { SISTEMÁTICA }\end{array}$} & \multicolumn{1}{c|}{ ETAPAS DA PESQUISA } \\
\hline $\begin{array}{l}\text { Definir o problema da } \\
\text { pesquisa }\end{array}$ & $\begin{array}{l}\text { O que está sendo abordado atualmente sobre o tema de economia } \\
\text { solidária no âmbito do design? }\end{array}$ \\
\hline Definir objetivo do trabalho & $\begin{array}{l}\text { Apresentar as principais publicações nos últimos dez anos, as } \\
\text { características desses estudos e os focos de conteúdos abordados, } \\
\text { permitindo a compreensão do estado da arte de pesquisas sobre a } \\
\text { economia solidária na perspectiva do design. }\end{array}$ \\
\hline
\end{tabular}




\begin{tabular}{|l|l|} 
Definir as palavras-chave & $\begin{array}{l}\text { Design; Economia Solidária; Economia Social; Empreendimento } \\
\text { Social; Cooperativismo. A busca foi efetuada aplicando os termos em } \\
\text { inglês }\end{array}$ \\
\hline Critérios de exclusão & $\begin{array}{l}\text { Foram estabelecidos os critérios de exclusão: 1) artigos repetidos; 2) } \\
\text { emprego do termo "design" como verbo ou substantivo, ou com } \\
\text { sentido não relevante à área de design; 3) emprego dos termos } \\
\text { "Solidarity Economy", "Social Economy", "Cooperativism", "Social } \\
\text { Enterprise" com sentido não relevante à contextualização de } \\
\text { Economia Solidária apresentada neste artigo. }\end{array}$ \\
\hline Conduzir buscas & $\begin{array}{l}\text { A busca foi realizada no Portal de periódicos da CAPES, utilizando } \\
\text { as combinações: "Design" AND "Solidarity Economy"; "Design" } \\
\text { AND "Cooperativism"; "Design" AND "Social Enterprise"; } \\
\text { "Design" AND "Social Economy". }\end{array}$ \\
\hline $\begin{array}{l}\text { Aplicar critérios para } \\
\text { seleção de artigos }\end{array}$ & $\begin{array}{l}\text { Os critérios de exclusão foram aplicados da seguinte maneira: Filtro } \\
\text { 1) Leitura dos títulos, resumos e palavras-chave dos artigos; Filtro 2) } \\
\text { Leitura da Introdução e Conclusão; Filtro 3) Leitura integral dos } \\
\text { artigos }\end{array}$ \\
\hline $\begin{array}{l}\text { Sintetização dos dados } \\
\text { obtidos }\end{array}$ & $\begin{array}{l}\text { Os artigos selecionados para constituírem a revisão sistemática foram } \\
\text { analisados integralmente. As informações consideradas relevantes } \\
\text { para este estudo, foram organizadas sinteticamente de acordo com as } \\
\text { categorias estabelecidas. }\end{array}$ \\
\hline Apresentação da discussão & $\begin{array}{l}\text { A partir da leitura e análise dos artigos selecionados, foi possível } \\
\text { identificar o estado do corpo de conhecimento da economia solidária } \\
\text { no âmbito do design. }\end{array}$ \\
\hline
\end{tabular}

Quadro 1: Etapas da Revisão Sistemática. Adaptado de Conforto, Amaral e Silva (2011).

A partir de uma revisão bibliográfica inicial, foram definidas as palavras-chave. O termo "Design" foi aplicado de forma generalizada, sem especificações da área, para atender ao objetivo de compreender qual é a perspectiva do design dentro do tema escolhido. Compreendemos que o termo utilizado para descrever o movimento conceituado, no Brasil, como Economia Solidária/Solidarity Economy, pode apresentar variações dependendo do país de origem dos autores. Portanto, com o intuito de ampliar o alcance dos resultados, foram selecionados os termos Economia Social/Social Economy, Empresa Social/Social Enterprises e Cooperativismo/Cooperativism.

A pesquisa foi conduzida no Portal de Periódicos da Capes, com uso da ferramenta de busca avançada. Foram aplicados os seguintes descritores: "Design" AND "Solidarity Economy"; "Design" AND "Cooperativism"; "Design" AND "Social Enterprise"; "Design" AND "Social Economy".

A busca foi refinada para apresentar apenas artigos revisados por pares, escritos em qualquer idioma e publicados no período dos últimos dez anos. Não foram selecionadas bases de dados específicas dentro do portal, devido à compreensão do caráter interdisciplinar desta revisão.

Para a análise dos artigos, foram estabelecidos os seguintes critérios de exclusão: 1) artigos repetidos; 2) emprego do termo "design" como verbo ou substantivo, ou com sentido não relevante à área de design; 3) emprego dos termos Economia Solidária/Solidarity Economy, Economia Social/Social Economy, Cooperativismo/Cooperativism, Empresa Social/Social Enterprises com sentido não relevante à contextualização de Economia Solidária apresentada neste artigo. 
As buscas resultaram em um total de 120 artigos, os quais foram submetidos ao primeiro filtro de análise, que consistiu na leitura dos títulos, resumos e palavras-chave, considerando os critérios de exclusão. A aplicação deste filtro resultou na seleção de 26 artigos.

Uma segunda análise foi efetuada com a nova seleção de artigos, desta vez aplicando os critérios de exclusão na leitura da introdução e conclusão (filtro 2). Em seguida, repetiu-se este processo com a leitura integral dos artigos resultantes (filtro 3).

\section{Resultados}

O resultado final da análise contabilizou oito artigos (Quadro 2), que foram então, submetidos à revisão para obtenção de dados e composição da discussão apresentada.

\begin{tabular}{|c|c|c|c|}
\hline AUTOR & ANO & TÍTULO & CATEGORIAS DE ANÁLISE \\
\hline $\begin{array}{l}\text { Riegel e } \\
\text { Zuchetti }\end{array}$ & 2011 & Design de Produtos e o Artesanato & $\begin{array}{l}\text { Economia Solidária; Artesanato; } \\
\text { Design de Produto }\end{array}$ \\
\hline $\begin{array}{l}\text { Mourão e } \\
\text { Engler }\end{array}$ & 2014 & $\begin{array}{l}\text { Economia Solidária e Design Social: } \\
\text { Iniciativas sustentáveis com resíduos } \\
\text { vegetais para produção artesanal }\end{array}$ & Economia Solidária; Design Social \\
\hline $\begin{array}{l}\text { Konsti-Laakso } \\
\text { et al. }\end{array}$ & 2016 & $\begin{array}{l}\text { Participatory Design of a social enterprise } \\
\text { for rehabilitees }\end{array}$ & $\begin{array}{l}\text { Empresa Social; Design } \\
\text { Participativo; Inovação Social }\end{array}$ \\
\hline Telalbasic & 2017 & $\begin{array}{l}\text { Redesigning the Concept of Money: A } \\
\text { service design perspective on } \\
\text { complementary currency systems }\end{array}$ & $\begin{array}{l}\text { Economia Solidária; Design de } \\
\text { Serviços; Inovação Social }\end{array}$ \\
\hline Cipriani & 2017 & $\begin{array}{l}\text { The emerging challenge of brand design } \\
\text { and brand management in social } \\
\text { innovations }\end{array}$ & $\begin{array}{l}\text { Empresa Social; Design de Serviços; } \\
\text { Inovação Social }\end{array}$ \\
\hline $\begin{array}{l}\text { Selloni e } \\
\text { Corubolo }\end{array}$ & 2017 & $\begin{array}{l}\text { Design for social enterprise. Co-designing } \\
\text { an organizational and cultural change }\end{array}$ & $\begin{array}{l}\text { Empresa Social; Coopeerativa; } \\
\text { Codesign; Design de Serviços; } \\
\text { Design Estratégicos; Inovação Social }\end{array}$ \\
\hline Chou & 2018 & $\begin{array}{l}\text { Applying Design Thinking method to social } \\
\text { entrepreneurship project }\end{array}$ & $\begin{array}{l}\text { Empreendedorismo Social; Design } \\
\text { Thinking; Design Social }\end{array}$ \\
\hline Kummitha & 2018 & $\begin{array}{l}\text { Institutionalizing design thinking in social } \\
\text { entrepreneurship: a contextual analysis into } \\
\text { social and organizational processes }\end{array}$ & $\begin{array}{l}\text { Empresa Social; Design Thinking; } \\
\text { Inovação Social }\end{array}$ \\
\hline
\end{tabular}

Quadro 2 - Artigos selecionados para revisão sistemática

Os artigos selecionados abrangem o período de publicação de 2011 a 2018. Identificou-se que os autores possuem filiações com instituições brasileiras (RIEGEL e ZUCHETTI, 2011; MOURÃO e ENGLER, 2014), estadunidenses (CHOU, 2018), italianas (CIPRIANI, 2017; SELLONI e CORUBOLO, 2017; KUMMITHA, 2018; TELALBASIC, 2017) e finlandesas (KONSTI-LAAKSO et al., 2016). Todos os artigos apresentam a metodologia de estudo de caso. 
De maneira geral, os artigos buscaram investigar como o design ou, quais abordagens do design, podem ser aplicadas para aprimorar a atuação de empresas sociais e/ou solidárias. Assim, observamos que o design foi contextualizado como uma área de conhecimento com a capacidade de propor mecanismos de análise, tanto dos processos internos dos empreendimentos, quanto do contexto em que se inserem, identificando os atores envolvidos e recursos disponíveis. Desta forma, o design poderia viabilizar novos processos, relacionamentos e interações, que resultem em soluções de problemas sociais fundamentais.

A partir da leitura dos artigos, os conceitos relevantes à esta discussão foram organizados em sete categorias. Apenas as palavras-chave Economia Solidária/Solidarity Economy e Empresa Social/Social Enterprises, aplicadas nas buscas, resultaram em uma categoria analítica. Os demais termos utilizados nas buscas não apresentaram resultados, portanto, não foram contemplados como categorias de análise.

Os conceitos observados após a revisão correspondem às outras seis categorias: inovação social; design thinking; design social; design de serviços e design estratégico; design colaborativo e design participativo; artesanato.

Sete artigos apresentam o conceito de inovação social para contextualizar tanto o desenvolvimento de empresas sociais, quanto a atuação do design. Foram identificadas referências às abordagens de design thinking, design social, design de serviços e design estratégico. Processos colaborativos/participativos do design são mencionados na maioria dos artigos, expressados como abordagens centrais para o processo de inovação social. Dois artigos descrevem detalhadamente a aplicação de ferramentas de design em processos colaborativos, como uma abordagem que viabiliza atingir maiores níveis de criatividade e colaboração entre os diversos atores na concepção e desenvolvimento de empreendimentos. Apenas um artigo apresenta o artesanato em sua discussão acerca da atuação do design em um empreendimento de economia solidária.

\section{Economia Solidária e Empresa Social}

A economia solidária é referenciada em dois artigos, ambos publicados no Brasil. Mourão e Engler (2014, p.332) descrevem o desenvolvimento deste movimento no Brasil, classificando-o como um "processo de aproximação do trabalhador com seus meios de produção", com objetivos de transformação social. As autoras relacionam a economia solidária ao design por meio do conceito de inovação social, na busca por soluções sustentáveis e reavaliação de formas organizacionais e produtivas.

O termo "empresa social" foi mais utilizado, sendo identificado em seis dos oito artigos analisados. Alguns autores optaram pelo distanciamento de definições teóricas sobre o tema, sendo, frequentemente, associado ao contexto mais amplo de inovação social.

Avaliando as definições propostas pelos artigos, podemos estabelecer que o termo "empresa social" é empregado para descrever iniciativas que combinam a lógica do mercado com objetivos sociais, atuando nas lacunas entre os setores privado e público, em um processo de criação de 
valor social, com o objetivo final de provocar mudanças culturais e atingir uma ordem social sustentável (KUMMITHA, 2018; KONSTI-LAAKSO, 2015; CHOU, 2018).

A admissão de uma avaliação tão ampla deste termo, nos permite incluir neste conceito, as experiências da economia solidária. Dito isto, devemos atentar-nos ao fato de que o contexto histórico, político, cultural e jurídico destes conceitos pode representar diferenças práticas na atuação dos empreendimentos, de acordo com seu país de origem. Moulaert e Ailenei (2005, p.2042) associam estas diferenças "às formas particulares de 'coexistência' (como as relações de cooperação, dependência ou controle) do setor privado, do público e do terceiro setor nos vários países, suas regiões e cidades".

A EMES ${ }^{1}$, uma rede europeia de pesquisa sobre empresas sociais, foi estabelecida com o propósito de investigar esta prática em diversos contextos da União Europeia, por meio de estudos teóricos e empíricos. Os pesquisadores oferecem um conjunto de indicadores que abrangem a heterogeneidade das empresas sociais. A dimensão econômica relaciona: a) produção contínua de bens ou serviços; b) alto grau de autonomia; c) nível significativo de risco econômico para os membros; d) mínimo de assalariados (combina trabalhadores remunerados e voluntários). A dimensão social relaciona: a) objetivo explícito de serviço à comunidade; b) originada a partir de um grupo de cidadãos; c) poder de decisão não baseado em capital (um membro, um voto); d) natureza participativa (BORZAGA e DEFOURNY, 2001).

A concepção de empresa social da EMES compreende um grande conjunto de experiências heterogêneas. Esta rede de pesquisa afirma que sua visão agrega os conceitos de empresa social, empreendedorismo social, economia social, economia solidária e inovação social (EMES, 2019).

Desta forma, compreendemos ser benéfico para este artigo, a análise dos estudos de caso que relatam as vivências das denominadas empresas sociais. Ressaltamos, porém, que a reprodução dos procedimentos e resultados apresentados, deve considerar as diferenças intrínsecas e extrínsecas das experiências em questão.

\section{Inovação Social}

O conceito de inovação social foi identificado em quase todos os artigos analisados, com exceção apenas do estudo de Riegel e Zuchetti (2011), que não relacionaram o conceito em sua investigação. De maneira geral, os autores utilizam o termo com o intuito de definir a esfera de atuação de empreendimentos que compreendem uma missão social, nem sempre oferecendo um aprofundamento teórico.

Identificamos que a definição de Murray, Caulier-Grice e Mulgan (2010, p.3) apresenta-se como uma das mais aceitas dentre os artigos. Propõe-se que se trata de "novas ideias (produtos, serviços, modelos) que, simultaneamente, atendem carências sociais e criam novas relações e colaborações sociais". Esta descrição nos leva à compreensão de que a inovação social é apresentada, nos artigos, como um conceito guarda-chuva, capaz de congregar as diversas

1 A sigla EMES representa "Emergence des Entreprises Sociales en Europe". Disponível em <https://emes.net/> 
experiências identificadas, que frequentemente se apresentam de forma heterogênea em suas constituições, contextos e processos.

O conceito de inovação social é atribuído à diversos estágios de um empreendimento. KonstiLaakso et al. (2016) utilizam o ponto de vista da inovação social para examinar a realização de um processo de design participativo para a criação e implementação de uma nova empresa social na área da saúde na Finlândia. Os autores enfatizam o processo de interações sociais como um aspecto importante da inovação social.

De maneira similar, Selloni e Corubolo (2017) discutem que a inovação social não se refere apenas à satisfação de necessidades sociais, está presente também na relação entre os diferentes atores e grupos sociais atuando em um processo. Assim, a inovação social não se encontra apenas na proposição de uma solução benéfica para a sociedade, mas principalmente, na forma como se atinge dito resultado.

Mourão e Engler (2014, p.333) afirmam que as "mudanças de padrões motivados pela recombinação de elementos efetuam o conceito de inovação social". As autoras não especificam a que se referem com "mudanças de padrões", mas podemos avaliar que sugestionam a inovação social como novas soluções que compõe um caminho para uma sociedade sustentável. Tal pensamento condiz com as ideias propostas por Manzini (2008, p. 25), que pondera que, para a nossa sociedade alcançar o desenvolvimento sustentável, será necessário um longo período de transição em que novas ideias devem ser geradas por meio de um extenso questionamento acerca do sistema vigente.

$\mathrm{Na}$ área do design, as experimentações na esfera da inovação social parecem estar direcionadas à aplicação de processos colaborativos, propondo que eventuais mudanças comportamentais devem ser impulsionadas, primordialmente, de baixo para cima.

Isto não expressa que o fluxo de ações e propostas de inovações sociais estão reservadas à ação de comunidades ou cidadãos comuns isoladamente. Propõe, primeiramente, a análise do contexto e a reestruturação dos relacionamentos entre pessoas e organizações (públicas ou privadas) envolvidas em um processo, para chegarem, conjuntamente, à uma solução adequada.

Esta concepção evidencia o papel da colaboração dentro deste processo, conforme observam Selloni e Corubolo (2017, p.3006), que caracterizam inovações sociais "pela colaboração entre uma variedade de atores, desde cidadãos ativos e associações locais até organizações privadas, instituições e empresas sociais".

\section{Design social}

O termo design social é utilizado por Chou (2017, p.74) para conceituar, de maneira sucinta, o "processo de design que contribui para o bem-estar humano e melhoria do sustento". Da mesma forma, Mourão e Engler (2014) ressaltam o objetivo principal de melhoramento da qualidade de vida como conceito central do design social. 
Não são atribuídas, nestes estudos, técnicas particulares ao processo do design social. O que se apresenta como mais relevante para a caracterização desta abordagem, é o objetivo final de atender as necessidades de grupos ou comunidades específicas, muitas vezes caracterizadas como periféricas, marginalizadas e excluídas, ou que não apresentam retorno financeiro para estimular a atuação do mercado formal.

Pazmino (2007, p.3) nos leva a compreender que um projeto de design social deve apresentar flexibilidade para empregar métodos, ferramentas e técnicas condizentes às características particulares da comunidade onde atua. Assim, deve almejar por obter resultados que, além de atender necessidades específicas, valorizem os aspectos sociais, culturais e ambientais locais, agregando uma proposta socialmente benéfica e economicamente viável.

\section{Codesign e Design Participativo}

De forma generalizada, podemos afirmar que a conceituação mais recorrente encontrada nos artigos analisados, foi do designer enquanto um mediador/facilitador de processos colaborativos. O design colaborativo é apresentado, dentro deste contexto, como um processo para obter resultados relevantes à inovação social e sustentabilidade na criação, implementação ou funcionamento de empreendimentos.

Identificamos a utilização dos termos "codesign" e "design participativo" em referência à inclusão de diversos atores em um determinado processo de design. Meroni et al. (2018) explica que os termos são equivalentes para descrever tal processo, sendo o termo "codesign" uma conceitualização mais recente.

Para Konsti-Laakso et al. (2016), que investigou as fases de idealização e implementação de uma empresa social, o design participativo representou uma forma de aprender com as pessoas, compreender como elas se sentem, o que pensam e como agem, gerando empatia no processo. Como os autores trabalharam com indivíduos sem experiência prévia em design ou empreendedorismo, as técnicas do design participativo (jogos lúdicos e improvisação) auxiliaram principalmente nas fases de ideação e de desenvolvimento de um novo empreendimento.

A proposta do campo de atuação do "design para empresas sociais", apresentado por Selloni e Corubolo (2017, p.3006), "sugere uma combinação de abordagens, métodos e ferramentas do design que sustentem a inovação em empresas sociais". As autoras adotaram abordagens do design colaborativo em dois workshops, que envolveram diversos atores ligados à atuação de cooperativas italianas. O propósito das técnicas do codesign, neste caso, foi o de compreender as diferentes perspectivas presentes e reforçar a colaboração entre todos os atores, incluindo trabalhadores, usuários, voluntários, funcionários públicos e decisores políticos.

Podemos destacar, mediante a leitura dos artigos, que processos colaborativos são particularmente interessantes para o desenvolvimento de empresas sociais/economia solidária. A colaboração é frequentemente indicada em conjunto à outras abordagens do design, quando discutida a criação de valor em um contexto de inovação social. Observamos, portanto, que a 
inclusão de designers (especialistas) no processo colaborativo de empreendimentos, tende a expandir as relações de colaboração, tornando-as mais produtivas e inovadoras.

Especialmente relevante para a discussão acerca de inovações sociais, Selloni e Corubolo (2017, p.3017) concluem que a atuação de empresas sociais na "conscientização sobre a importância de promover uma mudança tanto de um ponto de vista cultural quanto organizacional" é potencializada mediante o envolvimento de "comunidades de usuários e outros tipos de atores locais", tornando essencial a orientação de processos colaborativos neste âmbito.

\section{Design Thinking}

Os artigos de Kummitha (2018) e Chou (2017) apresentam estudos de caso que buscam identificar a aplicação da abordagem do design thinking nos processos internos de empresas sociais.

Ambos os autores destacaram as similaridades entre os processos organizacionais de empresas sociais e o processo de design thinking. Da mesma forma em que o processo de design thinking é centrado no humano e propõe uma imersão no contexto do problema a ser pesquisado como meio de gerar empatia, o sucesso de uma empresa social depende da compreensão acerca das necessidades das pessoas e comunidades impactadas pela atuação do empreendimento.

Por meio de estudos de caso, Kummitha (2018) identificou que o processo de design thinking já estava sendo aplicado nos empreendimentos, como uma forma de desenvolver soluções criativas para os problemas sociais das comunidades onde estavam inseridos. Todavia, os participantes destes processos não tinham conhecimento de que já estavam aplicando esta metodologia. Outro ponto importante é que em nenhum dos empreendimentos analisados foi identificada a presença de designers. Uma das principais razões atribuídas para a aplicação do design thinking, nestes casos, é a participação ativa da comunidade e usuários no dia a dia dos empreendimentos e ao longo de seus processos internos.

As conclusões propostas por Kummitha (2018) condizem com os resultados de Chou (2017, p.78), que aponta que "projetos de empreendedorismo social e a metodologia de design thinking são altamente relacionáveis em seus atributos e, portanto, podem ser integradas". O autor destaca como pontos de convergência entre os processos, os seguintes atributos: foco centrado no humano; estratégias e objetivos; abordagem de inovação; altruísmo; colaboração; envolvimento de usuário; prototipagem; testes; experimentação.

\section{Artesanato}

Dentre os artigos analisados, apenas Riegel e Zuchetti (2011) contextualizam a produção artesanal ao design de produto e à economia solidária. $\mathrm{O}$ artigo descreve a experiência de incubação de um empreendimento econômico solidário de artesãos, e relata a intervenção de designers no processo produtivo do empreendimento. 
Inserida no contexto de produção artesanal e economia solidária brasileira, a pesquisa afirma ocorrer, atualmente, uma valorização do fazer manual em relação aos processos de industrialização. $\mathrm{O}$ artesanato é proposto, portanto, como um resgate da identidade cultural e preservação da cultura tradicional.

É explorado no artigo a relação benéfica entre a área de design e o artesanato. Propõe-se que o trabalho artesanal se beneficia das abordagens metodológicas do design, resultando em produtos com melhor colocação no mercado e valorização de conhecimentos tradicionais.

As autoras identificaram que o artesanato está inserido em um mercado altamente competitivo, com grande oferta de produtos similares. Desta forma, a intervenção focou na melhoria dos acabamentos e qualidade geral do produto, explorando materiais e técnicas adequadas. Concluem que a excelência do produto artesanal é de maior importância para competir neste mercado, e que os valores propostos da economia solidária se apresentam como um diferencial competitivo.

\section{Design de serviços e Design estratégico}

Em sua análise acerca da construção de valor de marca de uma cooperativa italiana, Cipriani (2017) identificou, como principal desafio, a comunicação de valores ambientais e sociais equiparada à percepção de qualidade do produto por parte dos consumidores. Para lidar com este problema, a autora sugere em sua conclusão, a aplicação do design de serviços, porém, não oferece um aprofundamento sobre quais métodos e ferramentas poderiam ser utilizados neste processo.

Selloni e Corubolo (2017) indicam a combinação do design estratégico, design de serviços e codesign, como abordagens viáveis para o desenvolvimento de empresas sociais, com potencial de melhorar a qualidade das interações entre os atores envolvidos e apoiar a criação de parcerias inovadoras e inéditas. Esta concepção vai ao encontro da proposta de design estratégico para a sustentabilidade, conceituada por Mazini e Vezzoli (2003, p.856) como:

A capacidade de criar novas configurações de stakeholders e desenvolver um sistema integrado de produtos, serviços e comunicação que seja coerente com a perspectiva de sustentabilidade a médio-longo prazo, sendo, ao mesmo tempo, economicamente viável e socialmente apreciável hoje.

De maneira similar, Telalbasic (2017, p.41) sugere a integração de usuários no processo de design de serviços, atuando como codesigners e coprodutores. Em sua investigação a respeito de sistemas monetários complementares em países desenvolvidos e em desenvolvimento, a autora utilizou a abordagem do design de serviços para analisar o desempenho e as melhores práticas dentro desta categoria, concluindo que o design de serviços pode "contribuir com novas formas de praticar economias democratizadas".

\section{Discussão dos resultados}

Pesquisas acadêmicas que discutem precisamente o movimento da economia solidária no âmbito do design encontram-se em um estágio inicial. O recorte temporal deste estudo foi de dez 
anos, todavia, o resultado mais antigo identificado dentro das especificações da pesquisa, foi publicado em 2011, sendo que percebemos um maior número de publicações a partir de 2016. Apesar de apenas dois artigos fazerem menções diretas à economia solidária, compreendemos, mediante as leituras, que as experiências e conceituações apresentadas podem ser relacionadas à economia solidária, da forma como este movimento se manifesta no Brasil.

A partir da análise dos artigos e identificação dos conceitos relacionados, corroboramos a interdisciplinaridade do tema em questão. Podemos visualizar esta característica como uma oportunidade de agregar diferentes pontos de vista nesta discussão. Pazmino (2007, p.3) considera necessária a aproximação interdisciplinar nos estudos que integram questões sociais à pesquisa em design e, afirma que nesta ótica, a atuação do designer envolve a "aplicação de metodologia de desenvolvimento de produto que permita minimizar os problemas sociais, aplicação de ferramentas e técnicas de projeto adequadas além de um maior conhecimento de sociologia, psicologia, política pública e antropologia”.

Identificamos, na maior parte dos artigos analisados, que o papel do design é de mediador/facilitador/provocador para processos de inovação social e sustentabilidade. Esta concepção corresponde à definição oferecida por Manzini (2008, p.29), que descreve, então, as etapas projetuais no processo de transição para uma sociedade sustentável: imaginar, avaliar, comparar soluções alternativas e desenvolver soluções mais adequadas.

Os resultados dos estudos de caso apontam o impacto positivo do design na identificação de oportunidades para a concepção de um novo empreendimento (KONSTI-LAAKSO et al., 2016); na capacitação de empreendimentos existentes (MOURÃO e ENGLER, 2014); na promoção do bem-estar social e econômico do empreendimento (RIEGEL e ZUCHETTI, 2011); no aprimoramento de processos internos (KUMMITHA, 2018); no incremento da criatividade, da produtividade e da inovação (CHOU, 2018); no acolhimento de uma nova cultura (SELONI e CORUBOLO, 2017); na capacidade em criar uma marca forte, com valores relevantes ao consumidor (CIPRIANI, 2017); e na concepção de novas práticas de democratização da economia (TELALBASIC, 2017).

A partir da intervenção do design, também são apontadas questões que devem ser abordadas. Selloni e Corubolo (2017) afirmam que empresas sociais são participantes naturais da inovação social, todavia, identificam que as empresas estudadas (cooperativas do contexto italiano) estão presas em um alto nível de burocratização, prevalecendo o relacionamento com a administração pública (top-down) em detrimento ao protagonismo em comunidades locais, o que distancia o empreendimento de um processo de inovação social e mudança cultural. A reaproximação com as necessidades de comunidades e atores locais (bottom-up) pode ser efetuada, de maneira exitosa, mediante a utilização de abordagens do design (SELONI e CORUBOLO, 2017; KONSTILAAKSO et al., 2016).

Outro aspecto interessante à esta discussão é a observação de Cipriani (2017) acerca do processo de desenvolvimento de produto em empresas ligadas à inovação social. A autora elabora que grande parte destes empreendimentos tratam o desenvolvimento e comercialização de seus produtos como uma atividade secundária, sendo a atividade principal a inclusão social e econômica de seus membros. Sendo assim, os produtos também são consumidos de maneira 
secundária, ou seja, pelo seu valor social e não por suas qualidades físicas. Isto representa uma solução sustentável paliativa, mas não garante o desenvolvimento, autonomia ou até mesmo a sobrevivência de um empreendimento a longo prazo.

\section{Conclusão}

Baseando-se nos dados obtidos a partir desta revisão sistemática, é possível concluir que investigações acerca do tema proposto ainda se encontram em um estágio incipiente. Todavia, a análise das experiências de aplicação de métodos e ferramentas do design em empresas sociais, como visto na literatura analisada, demonstrou que a introdução de uma cultura de design resultou em experiências positivas, facilitando os processos internos de empreendimentos.

A análise dos artigos demonstrou que as pesquisas atuais sobre economia solidária ou empresas sociais no âmbito do design, buscam investigar meios de desenvolvimento sustentável de empreendimentos que compõem tais conceitos, em um contexto de inovação social. Assim, identificamos que foram feitas investigações e experimentações aplicando abordagens do design social, design thinking, design participativo ou colaborativo, design de serviços, design estratégico, ou uma combinação de métodos e ferramentas, de acordo com os objetivos propostos.

Ressaltamos que a heterogeneidade das formas organizacionais e seus respectivos contextos, descritos nos estudos de caso, representam um obstáculo para a sistematização de um design pensado para empresas sociais e solidárias.

Ainda assim, as conclusões dos autores revelam uma visão otimista e ressaltam o potencial de novas investigações acerca deste tema. Pesquisas nesta área representam um novo setor de atuação para o design, um que não trabalha necessariamente com a lógica do mercado tradicional ou com o terceiro setor. As especificidades deste setor demandam um olhar inovador frente aos desafios impostos. As empresas sociais e solidária, por sua vez, devem estar abertas às eventuais propostas e mudanças instigadas pelos designers.

\section{Referências}

ALIANÇA COOPERATIVA INTERNACIONAL. Cooperative identity, values \& principles, c2018. Disponível em: < https://www.ica.coop/en/cooperatives/cooperativeidentity>. Acesso em: 23 de Jan. de 2019.

BORZAGA, C.; DEFOURNY, J. The Emergence of Social Enterprise. London and New York: Routledge, 2001.

CHOU, D. C. Applying design thinking method to social entrepreneurship project. Computer Standards \& Interfaces, v.55, p.73-79, 2018.

CIPRIANI, T. K. The emerging challenge of brand design and brand management in social innovations. The Design Journal, v.20, n.1, p.3536-3545, 2017.

CONFORTO, E. C.; AMARAL, D. C.; SILVA, S. L. Roteiro para revisão bibliográfica sistemática: aplicação no desenvolvimento de produtos e gerenciamento de projetos. In: CONGRESSO BRASILEIRO DE GESTÃO DE DESENVOLVIMENTO DE PRODUTO CGBDP, 8., 2011, Porto Alegre. Anais... Porto Alegre: IGDP, 2011, p.1-12. 
DEFOURNY, J.; NYSSENS, M. Conceptions of Social Enterprise and Social Entrepreneurship in Europe and the United States: Convergences and Divergences. Journal of Social Entrepreneurship, v.1, n.1, p.32-53, 2010.

EMES INTERNATIONAL RESEARCH NETWORK. Focus areas, S.D. Disponível em: $<$ https://emes.net/focus-areas/>. Acesso em: 18 de Jan. de 2019.

FRANÇA, G. C. Terceiro Setor, Economia Social, Economia Solidária e Economia Popular: traçando fronteiras conceituais. Revista Bahia Análises \& Dados, Salvador, v.12, n.1, p.919, 2002.

KONSTI-LAAKSO, S. et al. Participatory design of a social enterprise for rehabilitees. Work, v.55, p.145-153, 2016.

KUMMITHA, R. K. R. Institutionalizing design thinking in social entrepreneurship: a contextual analysis into social and organizational processes. Social Enterprise Journal, v.14, n.1, p.92-107, 2018.

MANZINI, E. Design para inovação social e sustentabilidade: comunidades criativas, organizações colaborativas e novas redes projetuais. Rio de Janeiro: e-papers, 2008.

MANZINI, E.; VEZZOLI, C. A strategic design approach to develop sustainable product service systems: examples taken from the 'environmentally friendly innovation' Italian prize. Journal of Cleaner Production, v.11, p.851-857, 2003.

MERONI, A. et al. Massive Codesign: A proposal for a collaborative design framework. Milão: Franco Angeli s.r.l., 2018.

MOULAERT, F.; AILENEI, O. Social Economy, Third Sector and Solidarity Relations: a conceptual synthesis from history to present. Urban Studies, v.42, n.11, p.2037-2053, 2005.

MOURÃO, N. M.; ENGLER, R. C. Economia Solidária e Design Social: iniciativas sustentáveis com resíduos vegetais para produção artesanal. Interações, v.15, n.2, p.329-339, jul./dez. 2014.

MURRAY, R.; CAULIER-GRICE, J.; MULGAN, G. The open book of social innovation. London: The Young Foundation e NESTA, 2010.

NAMORADO, R. Cooperativismo. In: CATTANI, A. D. et al. Dicionário internacional da outra economia. São Paulo: Almedina, 2009. p.96-102.

PAZMINO, A. V. Uma reflexão sobre Design Social, Eco Design e Design Sustentável. In: SIMPÓSIO BRASILEIRO DE DESIGN SUSTENTÁVEL, 1., 2007, Curitiba. Anais... Curitiba: UFPR, 2007.

RIEGEL, S.; ZUCHETTI, D. T. Design de produto e o artesanato. Revista Conhecimento Online, v.1, p.22-32, 2011.

SELLONI, D.; CORUBOLO, M. Design for social enterprises. Co-designing an organizational and cultural change. The Design Journal, v.20, n.1, p.3005-3019, 2017.

SINGER, P. Introdução à Economia Solidária. 1. ed. São Paulo: Editora Fundação Perseu Abramo, 2002.

TELALBASIC, I. Redesigning the Concept of Money: a service design perspective on complementary currency systems. Journal of Design, Business \& Society, v.3, n.1, p.21-44, 2017.

WDO. Definition of Industrial Design, S.D. Disponível em: https://wdo.org/about/definition/. Acesso em: 12 de Out. de 2018. 


\section{Sobre as autoras}

\section{Renata Mayumi Lopes Fujita}

Doutoranda do Programa de Pós-Graduação em Design (FAU-USP); Mestre (2017) pelo Programa de Pós-Graduação em Têxtil e Moda (EACH-USP); pós-graduada (2012) em Moda e Criação pela Faculdade Santa Marcelina (Lato Sensu) e graduada em Negócios da Moda na Universidade Anhembi Morumbi (2010). Pesquisa, atualmente, os seguintes temas: abordagens e processos de design; economia solidária e moda.

mayumilf@usp.br

\section{Lara Leite Barbosa}

Professora Doutora do Departamento de Projeto da FAU-USP. Arquiteta e Urbanista (EESCUSP). Mestre em Tecnologia do Ambiente Construído (EESC-USP). Doutora em Arquitetura e Design (FAU-USP). Autora do livro "Design sem fronteiras: a relação entre o nomadismo e a sustentabilidade", publicado pela Edusp e Fapesp em 2012 - $1^{\circ}$ lugar no Prêmio do Museu da Casa Brasileira em 2009 e $3^{\circ}$ lugar do Prêmio Jabuti em 2013 na categoria Arquitetura e Urbanismo. Atualmente é a coordenadora do grupo NOAH- Núcleo Habitat sem Fronteiras, onde desenvolve e orienta pesquisas sobre Design para situações emergenciais.

barbosall@usp.br 